\title{
FIELD-FLOW FRACTIONATION OF CHROMOSOMES
}

\section{Progress Report}

for Period February 1, 1990 to January 31, 1991

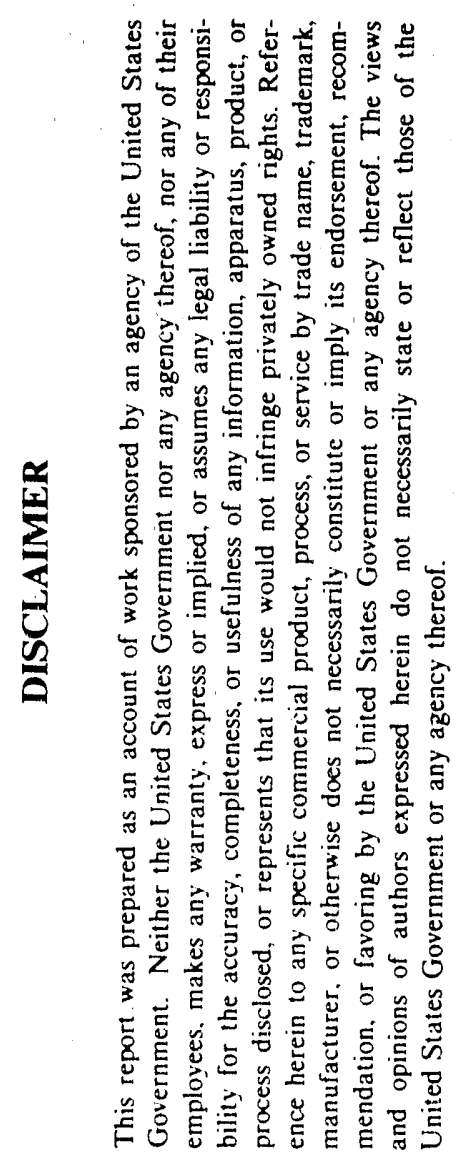

\author{
J. Calvin Giddings
}

University of Utah

Salt Lake City, Utah 84112

September 1990

Prepared for

The U.S. DEPARTMENT OF ENERGY

AGREEMENT NO. DE-FG02-89ER60851

DISTRIBUTION OF THIS DOCUMIENT IS UNLIMITED 


\section{Progress Report}

Progress in the past year can be organized into three main categories: (1) chromosome sample preparation; (2) preliminary chromosome fractionation; (3) fractionation of a polystyrene aggregate model which approximates the chromosome shape.

\section{Chromosome Sample Preparation}

The isolation of metaphase chromosomes has proved to be unexpectedly challenging, possibly due to problems of experience and equipment. Although we received collaborative assistance and advice from researchers in the University departments of pathology, biology, and human genetics, our attempts to isolate chromosomes from drosophila, melanogaster, onion, and human blood cells met with little success.

More recently, with advice from the Biomedical Sciences Division of Lawrence Livermore National Laboratory and the Life Sciences Division of Los Alamos National Laboratory, we have been successful in isolating metaphase chromosomes from the Chinese hamster. We also received a human chromosome sample from Dr. Carolyn Bell-Prince of Los Alamos National Laboratory.

The procedure for isolation of chromosomes from the Chinese hamster was provided by Dr. Barbara Trask (Lawrence Livermore National Laboratory). Don cell line (ATCC) cells were grown in McCoy's medium SA supplemented with $10 \%$ fetal calf scrum in a $37^{\circ} \mathrm{C}, 5 \% \mathrm{CO}_{2}$ incubator. The cells were metaphase arrested by adding colcemid to the culture medium to a final concentration of $0.1 \mu \mathrm{g} / \mathrm{mL}$ and incubating for $4 \mathrm{hrs}$. The cells were then swollen in a hypotonic solution containing $40 \mathrm{mM} \mathrm{KCl}, 0.2 \mathrm{mM}$ sperminc, and 1 
mM spermidine. Metaphase chromosomes were released from swollen cells by vortexing in isolation solution. Using this method, we have recently prepared chromosomes of Chinese hamster suspended in isolation solution.

Increasing collaboration with the two National Laboratories along with gains in our own experience appear to have brought us to the point where we will now have adequate supplies of metaphase chromosomes to pursue our main project objective--chromosome fractionation.

\section{Preliminary Chromosome Fractionation}

An in-house sedimentation FFF system of the type typically used for steric mode separations has recently been applied to the newly prepared chromosomes. The channel of the system is $86.5 \mathrm{~cm}$ in length, $2 \mathrm{~cm}$ in breadth, and $0.01270 \mathrm{~cm}$ in thickness. Either a UV or a fluorescence detector (with chromosomes stained by DAPI) is being used.

Scveral carricr solutions were investigated for the fractionation of chromosomes. A $10 \mathrm{mM}$ Tris buffer has been the most successful. In the $\mathrm{pH}$ range of 7.5-9.0, a broad retained peak of a human chromosome sample (from LANL) appears (Figure 1). The width of the peak seems to depend on $\mathrm{pH}$. The experiments thus far have been carried out at room temperature; however, the chromosomes may be more stable at lower temperatures. The effect of temperature as well as the bchavior of various buffer preparations are currently being studied. Microscopy is now being used to cxamine eluted fractions in order to characterize the migration and separation characteristics of different groups of chromosomes.

Trial chromosome fractions were also carricd out in a flow FFF channel $(33 \mathrm{~cm} \times 2 \mathrm{~cm} \times 2.06 \mathrm{~cm})$ with a frit injection capability. The carricr for the Chinese hamster chromosomes was a $25 \mathrm{mM}$ Tris- $\mathrm{HCl}$ buffer of $\mathrm{pH} 7.56$ 




Figure 1. Sedimentation/steric FFF fractogram of Chinese hamster chromosomes in a $10 \mathrm{mM}$ Tris buffer carrier of $\mathrm{pH} 8.5$. Flowrate $4.90 \mathrm{~mL} / \mathrm{min}$;
ficld strength $107 \mathrm{G}$. 
containing $1.0 \mathrm{mM} \mathrm{MgCl} 2$ and $0.5 \mathrm{mM} \mathrm{CaCl}_{2}$. The chromosome peak was slightly retained $(R=0.678)$. Fractions were collected from a run with a more concentrated sample; the fractions were examined under the microscope. The first fraction eluting contained aggregates while later fractions coutained some chromosomal fragments. These very preliminary results indicate the need to identify a carrier buffer which both stabilizes and disperses the chromosomes.

\section{Fractionation of a Polystyrene Aggregate Model}

Many metaphase chromosomes are roughly cylinder-shaped (or capsule-shaped) with a cylinder length greater than the diameter. Within a species, it is common to find chromosomes of fairly uniform diameter, differing mainly in length. Field-flow fractionation theory predicts that particles of the shape mentioned can be serurated by virtue of both the differential driving forces of FFF and the unequal hydrodynamic lift forces opcrative in the steric mode.

To confirm the predictions of theory we have prepared aggregates of 2.0 $\mu \mathrm{m}$ polystyrene latex beads; the singlet and the doublet closcly resemble different Chinese hamster chromosomes in size and shape. Figure 2 shows that it is possible to fractionate the singlet, doublet, and higher aggregate particles. Peak 3 is the singlet peak, Peak 2 is the doublet, and Peak 1 contains the higher aggregatcs. The identification of the peaks has been confirmed by electron microscopy. Because separation is highly dependent on the lift forces, which in turn depend on flowrate, the proper adjustment of flowrate and field strength is critical for optimization.

The above results not only demonstrate the inherent feasibility rif fractionating chromosomes by FFF, but show that chromosomal age, cgates can 


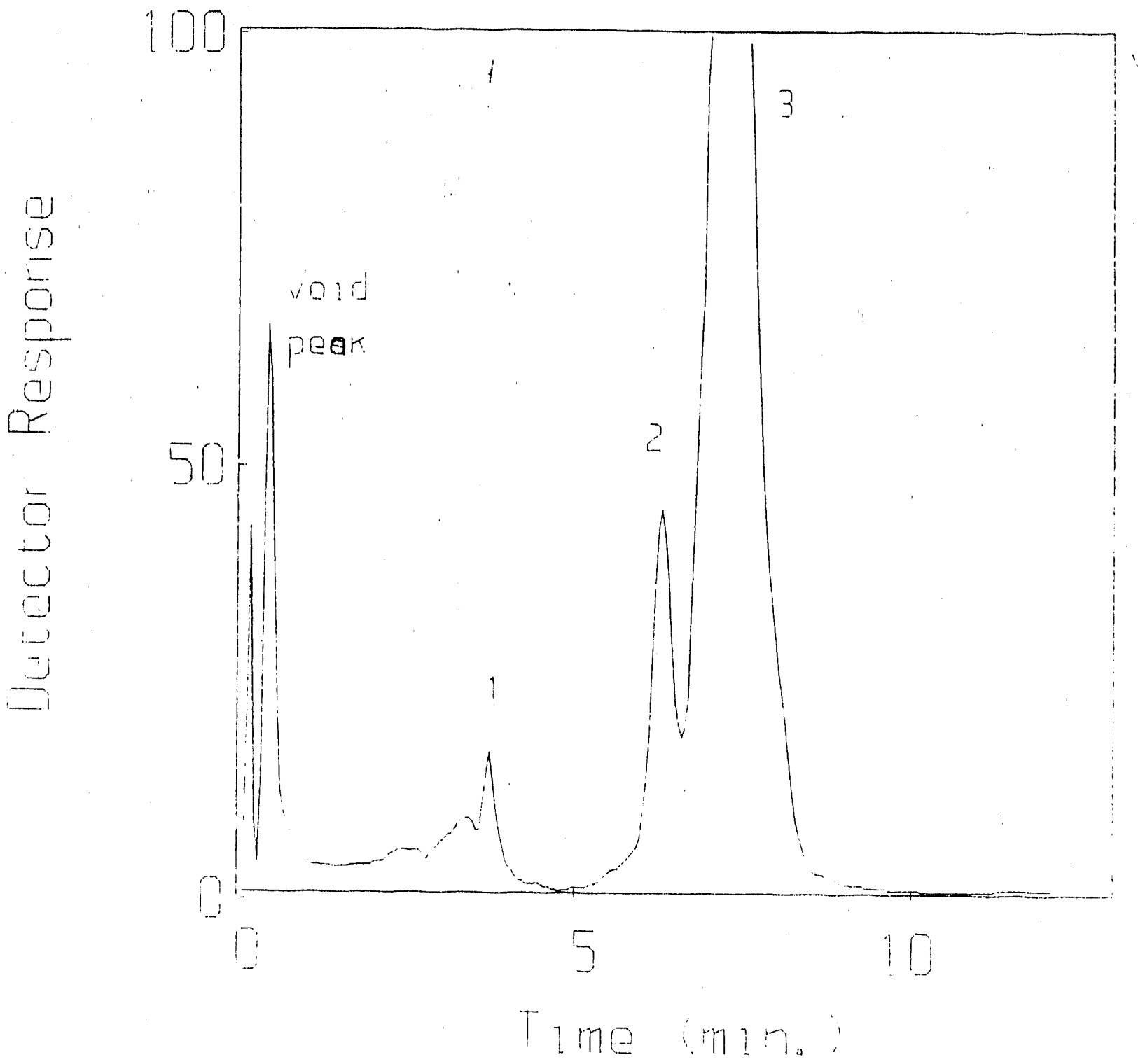

Figure 2(a). Sedimentation/steric FFF fractogram of aggregates of $2.0 \mu \mathrm{m}$ polystyrene latex beads. Carrier $0.1 \%$ FL-70; flowrate $10.0 \mathrm{~mL} / \mathrm{min}$; ficld strength $540 \mathrm{G}$. 


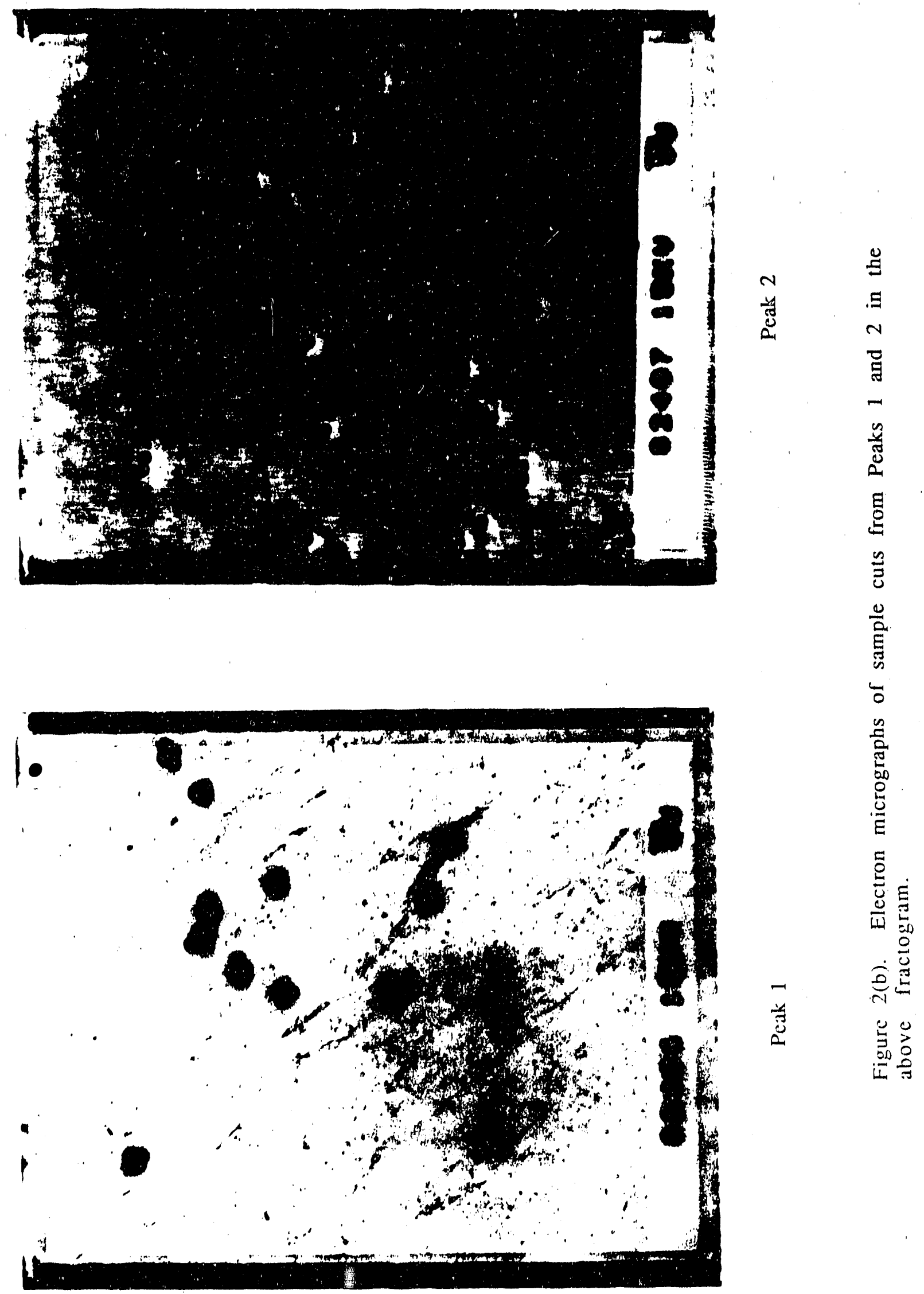


be separated from single chromosomes. This capability by itself would be extremely important among the steps needed to prepare pure chromosomes. 

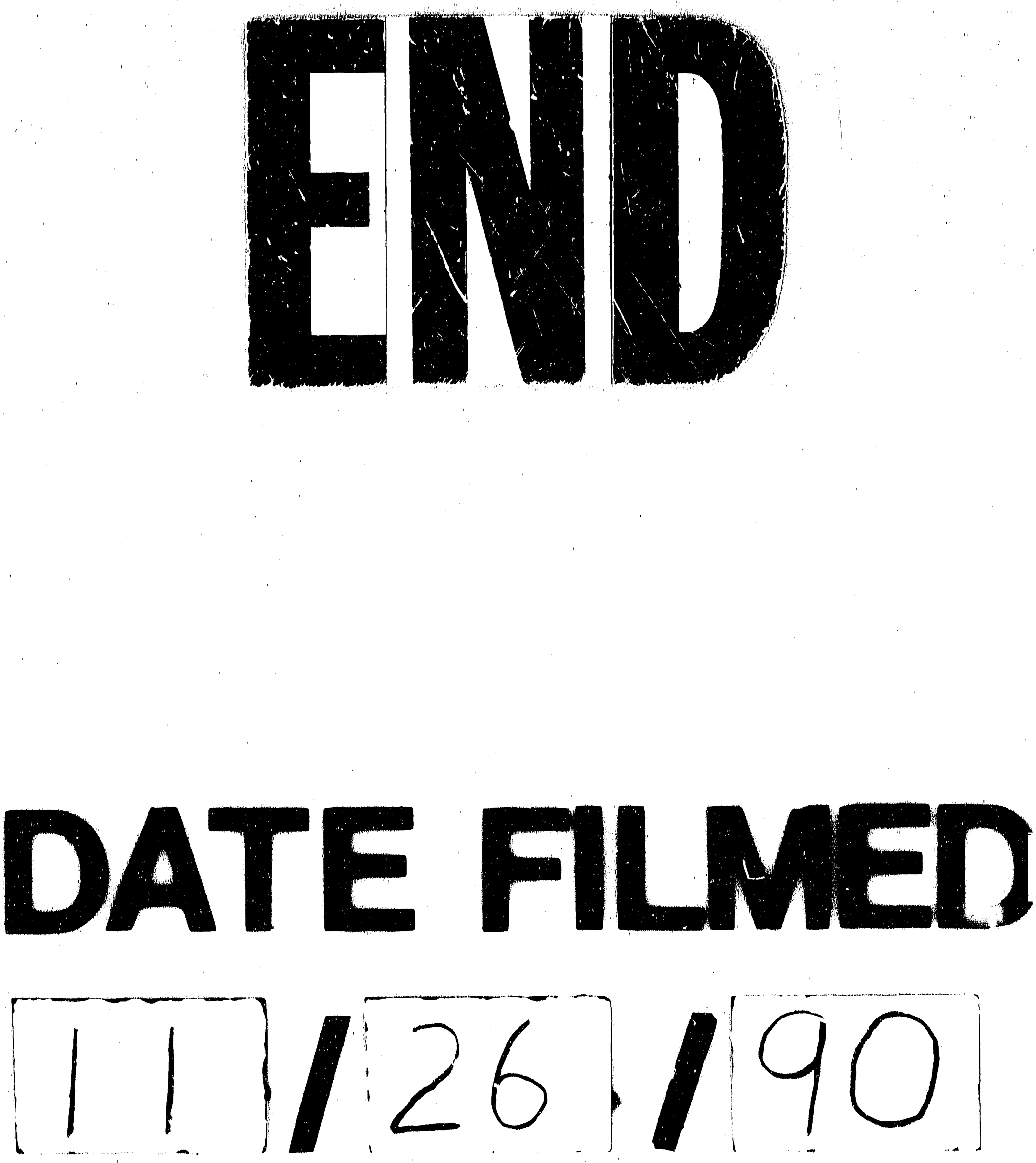
